\title{
Diversity due to mutations in circulating virus strains of SARS- CoV-2 may delay control of COVID-19
}

\author{
Sharanagouda S. Patil ${ }^{1}$, Chandan Shivamallu ${ }^{2 *}$, Chandan Dharmashekara ${ }^{2}$, Sushma Pradeep ${ }^{2}$, Kuralayanapalya Puttahonnappa \\ Suresh $^{1}$, Ashwini Prasad ${ }^{3}$, Shiva Prasad Kollur ${ }^{4}$, Mahendra P. Yadav ${ }^{5}$, Chandrashekar Srinivasa $^{6}$, Bramhadev Pattnaik ${ }^{7}$ \\ ${ }^{1}$ ICAR-National Institute of Veterinary Epidemiology and Disease Informatics NIVEDI, Bengaluru, India. \\ ${ }^{2}$ Department of Biotechnology and Bioinformatics, Faculty of Life Sciences, JSS Academy of Higher Education and Research, Mysuru, India. \\ ${ }^{3}$ Department of Microbiology, Faculty of Life Sciences, JSS Academy of Higher Education and Research, Mysuru 570 105, Karnataka, India. \\ ${ }^{4}$ Department of Sciences, Amrita School of Arts and Sciences, Amrita Vishwa Vidyapeetham, Mysuru Campus, Mysuru 570 026, Karnataka, India. \\ ${ }^{5}$ Sardar Vallabhbhai Patel University of Agriculture amp; Technology, Meerut, Uttar Pradesh, India. \\ ${ }^{6}$ Department of Studies in Biotechnology, Davangere University, Shivagangotri, Davangere 577002, Karnataka, India. \\ ${ }^{7}$ ICAR-DFMD and FAO Ref Centre for FMD in South Asia, Mukteswar, Nainital, Uttarakhand-263138, India.
}

\section{ARTICLE INFO \\ Article history: \\ Received on: August 30, 2021 \\ Accepted on: November 20, 2021 \\ Available online: February 15, 2022}

Key words:

SARS-CoV-2, COVID-19,

RNA viruses, Quasispecies, neutralization escape mutants,

Non-structural proteins,

Serosurveillance, DIVA/ DIVI.

\section{ABSTRACT}

Severe acute respiratory syndrome (SARS)-coronavirus-2 (CoV-2) is a beta-coronavirus (beta- CoV; sarbecovirus), like its predecessors SARS and MERS CoVs. Of the structural proteins of the virus, the Spike (S) protein on the virion envelope binds to the host cell ACE2 through viral epitopes in the receptor-binding domain (RBD). Deletions in the ORF8 as well as mutations in the S gene of SARS-CoV of 2003 were related to adaptation of the virus to humans. The emergence of novel variants of SARS-CoV-2, viz., B.1.1.7, B.1.427 and B.1.429, B.1.617 and its Kappa and Delta strains/ variants, B.1.351, and P.1 in the United Kingdom, Americas, India, South Africa and Brazil, respectively, has been found be associated with the current waves of the COVID-19 pandemic. These variants are antigenically dissimilar, whereas the current COVID-19 vaccines are monovalent. This is a handicap in the control program. The Delta variant has been reported in 74 countries as of 14 June 2021 and the anticipated third wave involving this variant is of concern to the countries (www.gavi.org). Of late, on 17 June 2021, Delta Plus variant was identified in India (AIIMS, Bhopal, India). Circulation of virus in vaccinated population may lead to endemicity, and this can be monitored by regular serosurveillance for antibodies against select non-structural proteins (NSPs) of the virus; antibodies to NSPs will indicate virus replication in the host. Endemic areas will have higher NSP reactors. It is predicted that the Delta B.1 variant may ignite the third wave of the disease in many countries. As it has been difficult to achieve uniformity in time and density of the vaccination even in the districts, circulation of the virus in partially immune population may lead to the selection of newer variants of SARS-CoV-2. The presence of monoclonal antibody resistant mutants and neutralization - escape mutants in quasispecies structure of another + sense RNA virus, i.e., Aphthovirus (FMD virus; foot and mouth disease virus) in the family Picornaviridae is well documented. The situation could be similar in the Coronaviridae member SARS-CoV-2. Previous immunity may not protect against current/ future mutants thereby pro-longing the COVID-19 control Programme.
\end{abstract}

\section{INTRODUCTION}

Diverse genera of viruses having RNA genome, viz., coronavirus (coronaviridae), aphthovirus, rhinovirus and enterovirus (picornaviridae), morbillivirus and parainfluenza virus (paramyxoviridae), pneumovirus and respiratory syncytial virus

*Corresponding Author

Chandan Shivamallu, Department of Biotechnology and Bioinformatics, Faculty of Life Sciences, JSS Academy of Higher Education and Research, Mysuru, India.E-mail: chandans@jssuni.edu.in (pneumoviridae), flavivirus and pestivirus (flaviviridae), alphavirus (togviridae), filovirus (filoviridae), influenza A virus including avian influenza (orthomyxoviridae), reovirus (reoviridae), and Lentivirus (retroviridae) cause variety of diseases in man and animals challenging One Health. These viruses contain an RNA genome that is either single stranded positive sense or negative sense, segmented negative sense or double stranded segmented International Committee on Taxonomy of Viruses (ICTV). The coronavirus disease 2019 (COVID-19) caused by SARS-CoV-2 was first identified in Wuhan, China at the end of December 2019. Coronaviruses of the subfamily Orthocoronavirinae, divided 
into four genera: Alpha-coronavirus, Beta-coronavirus, Gammacoronavirus, and Delta-coronavirus [1]. The ss-RNA genome of the SARS-CoV-2, a beta- CoV, is comprised 29,891 nucleotides $(7,986 \mathrm{aa})$ that make four viral structural proteins (SPs), several non-structural proteins (NSPs) and accessory proteins (Fig. 1) $[2-4]$.

The Spike (S) gene of CoVs is variable in the nucleotide sequence, and the glycoprotein is important for virus entry into susceptible host cells and initiation of pathogenesis. In phylogenetic analysis, two subtypes of SARS-CoV-2 (SARS-CoV-2a and -b) divided by a novel mutation of $\mathrm{D} \rightarrow \mathrm{G}$ at codon 614 (b subtype has $614 \mathrm{G})$ located in a B-cell epitope in the S1 domain, have been confirmed. SARS-CoV-2b (614G ) is reported to have reduced immunogenicity compared to SARS-CoV-2a (614D) and might lead to persistent or recurrent infection, and a vaccine having both the subtypes may be more effective [5].

Major NSPs of the virus, viz., NSP3 (PL- protease), NSP5 (CLprotease), NSP12 (RdRp), and NSP13 (helicase/triphosphatase) have enzymatic functions during virus replication [6-8]. The 33.8-kDa 3-chymotrypsin-like cysteine protease (3CLpro; NSP5) cleaves nascent polyproteins pp $1 \mathrm{a}$ and pp $1 \mathrm{ab}$ to functional polypeptides at 11 conserved sites, including autolytic cleavage of the 3CLpro from the polyproteins [9]. The 3CLpro also plays a major role in the pathogenicity of the virus/ disease [10]. This NSP is a target for antiviral therapy, and also can be used for differentiation of infected/ superinfected from those vaccinated (DIVA in veterinary epidemiology, meaning "differentiation of infected from vaccinated animals") humans during the current COVID-19 vaccination regime. Most of the new generation subunit COVID-19 vaccines that carry components of the Spike gene/ sequence must be DIVI (differentiation of infected from vaccinated individuals) compatible by nature; meaning individuals vaccinated with such a vaccine (DIVI compatible) will not have detectable antibodies (in serum) against any NSP of the virus, until unless pre-infected/convalescence or superinfected following vaccination. Application of DIVI diagnostics in the enzyme-immunoassay platform would be handy in monitoring live virus circulation in vaccinated areas. Recovery from COVID-19 did not rule out re-infection. Reinfection has been frequent, and its prevention in convalescent people is an important control measure [11].

CoVs infect animals, poultry birds, and humans, causing respiratory, gastrointestinal, hepatic, and neurologic disorders. Infectious bronchitis (IB) of poultry caused by a gamma-CoV (IBV) was first described in 1930s. Electron microscopic structure of Infectious Bronchitis Virus [12], a gamma-CoV, helped in diagnosing SARS virus in 2002-03 as a Coronavirus. Mutations in CoVs are related to changes in mode of virus excretion and transmissions. Among the known CoVs, seven have been identified to be infecting humans; three belong to the Genus beta-coronavirus responsible for the outbreaks of SARS (2002-03, in Guangdong, China), MERS-CoV (2012-13 in Saudi Arabia), and COVID-19 since 2019 [8,13]. The beta-CoVs target both the upper respiratory tract and lungs [14]. Unlike SARS-CoV-1, the SARS-CoV-2 also replicates in neurons of COVID-19 patients and may cause neural symptoms rarely reported in SARS-CoV patients [15]. The SARS-CoV-2 is excreted in respiratory discharges and the virus contaminated droplets from both asymptomatic and clinically sick people remains viable up to an hour in the air; air movement can disperse and transport the virus to distant places [16]. Aerosol spread of the virus resulting in higher infection rates $(\mathrm{R} 0>1.5)$ has been conspicuous in the second surge of the COVID-19 infection in India. The present compilation summarises genetic variations occurring in the RNA genome of the SARS-CoV-2, and its possible effect on control of COVID-19.

\subsection{Genome Organisation of SARS-CoV-2}

The organization of the viral RNA genome is: 5'-L-UTRspolumerase-Spike-Env-Membrane-Nucleocapsid-3'UTR-poly(A) [3]. In addition to 4 SPs, the genome codes for 16 NSPs (NSP 1-16), and 9 other accessory proteins [17]. Major NSPs are 3, 5, 12, and 13 shown in Figure 1.

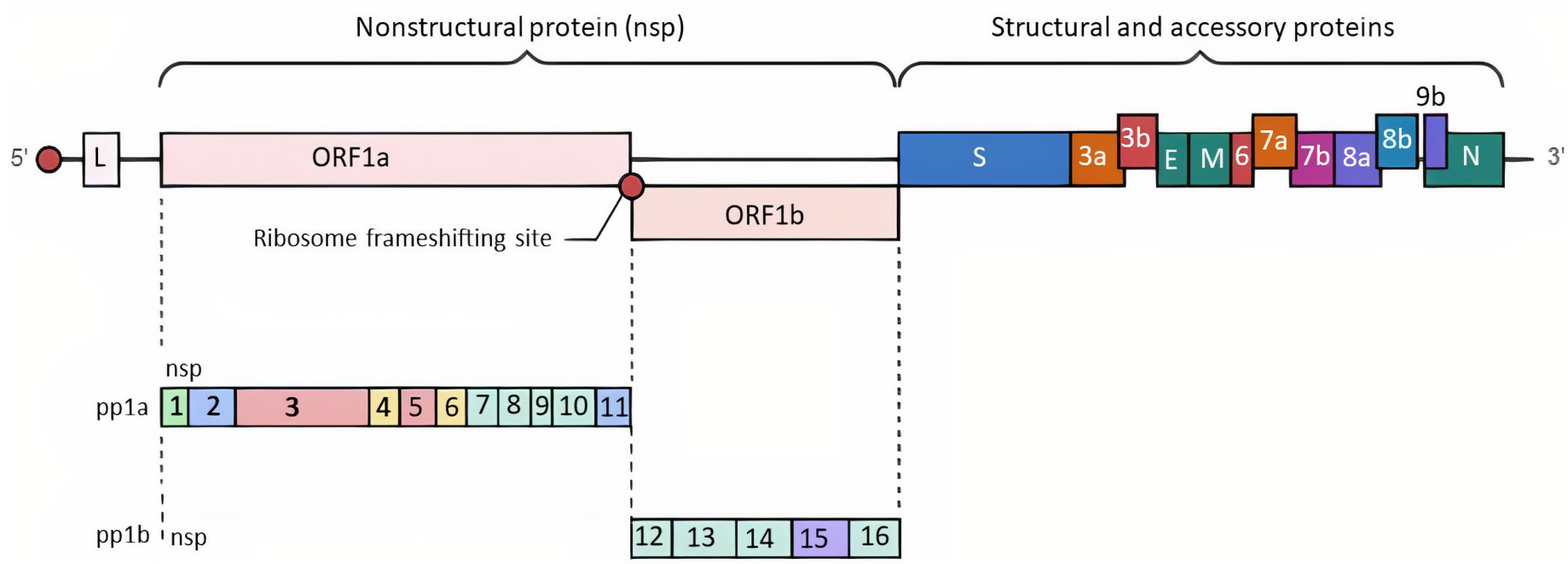

Figure 1: Genomic organization of SARS-CoV-2 indicating the location of ORFs, SPs, NSPs and accessory proteins. 


\subsection{Mutations/Deletions/Diversity in SARS-CoV-2}

Cao et al. (2021) analysed 1962 high-quality genomes of SARSCoV-2 strains obtained between 23 December 2019 and 21 March 2020 and recorded genetic variations between them.

Frequency of variation in $>1900$ SARS-CoV-2 genome samples examined varied from 5.48 in coding regions to 6.96 in the noncoding regions [18]. The variation sites included S: 23403 (D614G), ORF1ab: 14408 (NSP12b: P314L), 17747 (NSP13: P504L) and 17858 (NSP13:Y541C), and ORF8: 28144 (L84S).

Mutations and evolution of the Spike gene have been elaborated [19]. Two deletions of 3 and 24 nts in ORF $1 \mathrm{ab}$ and a single deletion of 10 nts in the $3^{\prime}$ end of the RNA genome was detected in the virus from Japan, USA and Australia. Out of 93 mutations detected, three (D354, Y364, and F367) were located in RBD. Mutations in the $\mathrm{S}$ protein may cause changes in the conformation of antigenic determinants/ epitopes leading to change in the antigenic nature of the virus. It is important to identify amino acid residues involved in the conformation of the spike glycoprotein [20]. Several nonsynonymous mutations were detected in the transmembrane and C-terminus domains of the envelope (E) protein in 15 of 3617 SARS-CoV-2 genomes analysed [21].

The viruses tend to evolve to circumvent host immune response. B cell epitopes in the $\mathrm{S}$ and $\mathrm{N}$ proteins have higher diversity than nonepitope positions. Mutations arise as a natural by-product of viral replication. Coronaviruses, however, make fewer mutations than most RNA viruses because they encode an enzyme that corrects some of the errors made during replication. In most cases, the fate of a newly arising mutation is determined by natural selection $[22,23]$. Mutations leading to aa replacements were detected in the RBD of the $\mathrm{S}$ gene. In RBD, highly antigenic epitopes had A348V, V367F and A419S [24]. With adaptive mutation of SARS-CoV-2 and the possibility of 'original antigenic sin', the effectiveness of the subunit vaccines could be compromised [25].

There was association of mutation in ORF3a with higher mortality rate [26]. One hundred ninety-eight (198) recurrent mutations were identified in the genome, the majority of which were nonsynonymous, suggesting possible adaptation in humans [27].

Thirteen sites of variation in ORFs 1a, 1b, Spike, 3a, Membrane, 8 , and Nucleocapsid regions were detected, suggestive of selective mutations in the virus [28]. Genotyping analysis revealed that the genes encoding the Spike protein, RdRp enzyme, RNA primase, and nucleoprotein, undergo frequent mutations [29]. In Vietnam, most common variants were C3037T, C14408T (NSP12: P323L) and A23403G (S gene: D614G) mutations [30]. The D614G virus was preponderant in Vietnam (Fig. 2). The SARS-CoV-2 lineages of A, B, B.1, B.2, B.3, and B.6 were detected in Malaysia. Su et al. (2020) reported deletion of a stretch of 382-nucleotide that truncated both ORFs $7 \mathrm{~b}$ and 8 . The earliest detection of such 382-nt deletant was identified in Singapore in 2020, January. Subsequently, SARS-CoV-2 with the same and other ORF7b/8 deletions have been detected in Taiwan, Australia, Bangladesh, and Spain. A new rapid spreading variant in the UK was identified with multiple mutations in the $\mathrm{S}$ gene, including $501 \mathrm{~N}$ to $\mathrm{Y}$ and deletion of histidine and valine codons (6 bases) at positions 69

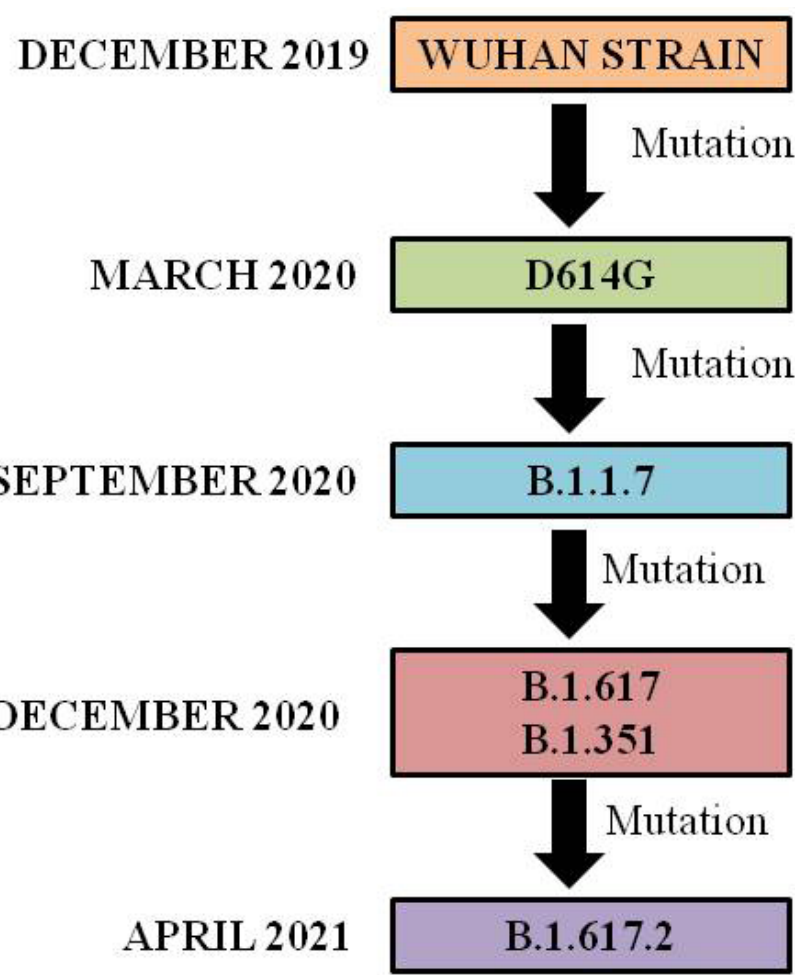

Figure 2: Year wise timeline of the emergence of COVID-19 variants.

and 70, respectively [32]. The WHO of the UN announced on 31 May 2021 the new naming system for significant COVID-19 variants based on Greek alphabet system, viz., Alpha (B.1.1.7; U.K.), Beta (B.1.351; South Africa), Gamma (P.1; Brazil and Japan), Delta (B.1.617.2; India), Epsilon (B.1.429 and B.1.427), Kappa (B.1.617.1; India), and Eta (B.1.525) etc, and informed that the Delta variant strain B.1.617.2 of the B.1.617 variant has higher transmission rate, whereas the other 2 strains of B.1.617.1 and B.1.617.3 have lower rates of transmission. The variant B.1.617 was first detected in India, which comprised of three strains, B.1.617.1 (kappa), B.1.617.2 (delta), and B.1.617.3. The Delta variant B.1.617.2 has a higher infection rate, and has already been reported in 62 countries (Fig. 2). It is known that some of the COVID-19 vaccine brands have already updated their vaccines to antigenically cover the delta variant. The different lineages/ variants of SARS-CoV-2, detected in different parts of the World, vary in Spike gene sequences on account of point mutatiomns/ deletions [33-39].

\subsection{Spike Glycoprotein and Molecular Evolution}

The COVID-19 with first incidence in December 2019 China has subsequently emerged rapidly worldwide. The spike (S) glycoprotein on the envelop of the virus is responsible for initiating the infection process through binding to the ACE2 present on variety of human cell types, and the degree of infectiousness of the disease is attributed to the nature/ composition of the $\mathrm{S}$ glycoprotein. The $\mathrm{S}$ protein of CoVs has two domains; the S1 domain carries RBD whereas S2 mediates subsequent fusion of viral and host cell membranes [40]. 
Subsequent to the initial Wuhan strain of the virus, SARS-CoV-2 strains with substitution of the amino acid residue D614 to G614 (Fig. 2) have been widely prevalent in the World. The S protein with G614 is more stable and more infectious than that with D614 [41]. The B.1.617 variant first detected in India exists as three strains, namely, B.1.617.1, B.1.617.2, and B.1.617.3. Recently, a P.2 variant virus B.1.1.28.2 isolated in India from International travellers could not be effectively neutralized by hamster serum antibodies raised against the B.1 variant with D614G [42]. The $\mathrm{S}$ gene nucleotide sequences of all these variants were obtained from GISAID, and evolutionary mutations in the spike gene/ protein were analysed using MEGA (Molecular Evolutionary Genetics Analysis) software and shown in Tables 1 and 2. The variant B.1.617 and its three strains that have G614 are rich in basic amino acid residues of Arginine and Lysine (Tables 1 and 2), making them more infectious compared to the Wuhan strain. The neighbourhood joining algorithm was used to estimate the Phylogenetic relationships that show that the Wuhan strain, and the variant B.1.617 and its three variant strains are genetically different (Fig. 3).

\subsection{Susceptibility}

COVID-19 has disproportionately affected minority ethnic populations in the UK. Some minority ethnic populations in England have excess risks of testing positive for SARSCoV-2 and of adverse COVID-19 outcomes compared with the White population, even after accounting for differences in sociodemographic, clinical, and household characteristics. Causes are likely to be multifactorial, and delineating the exact mechanisms is crucial [43].
Tissue tropism of virus depends on the complementary receptor available on the host cells' surface. The S protein of SARSCoV-2, unlike HCoVs NL63 and 229E and SARS-CoV-1, has a host Furin(s) cleavage site having multiple Arginine amino acid residues that facilitates the release of virus RNA genome in to the cells, thereby more infectious than the earlier SARS virus of 2002-03 [44]. Neuropilin-1 that binds to furin-cleaved polypeptide chains enhances infectivity of SARS-CoV-2 [45]. With the drastic rise in the COVID-19 cases around the Globe, the WHO of the UN emphasized the assessment of the risk of spread and understanding possible genetic modifications in the SARS-CoV-2 (www.who. in). Several point mutations/ SNPs were detected all across the SARS-CoV-2 genome, more so in the Spike, NSP1, RdRp and the ORF8 regions of the virus genome, and all these genetic variations/ changes could be attributed to altered virulence with higher morbidity and mortality [46].

The landscape genetics has an important role in shaping COVID-19 dynamics, with the involvement of multiple host and virus genes in the processes of virus entry, infection and immunological response. Three genetic gateways to the SARSCoV-2 infection have been described [47]; (1) variations within ACE2 gene, (2) HLA (Human Leukocyte Antigen) locus, and (3) host genes regulating Toll-like receptor, inflammation and complement pathways that are critical in determining the risk, severity, and outcome of COVID-19. Genotypes of Angiotensin converting enzyme (ACE) are related to mortality in COVID-19. The ACE gene consists of two variant alleles that are insertion and deletion, in short, I and D, polymorphisms [48]. There are 03 distinct ACE genotypes; II, ID, and DD [49]. Discrepancies in spread, severity, and mortality in COVID-19 could be attributed to

Table 1: Nucleotide composition of the virus strains in the spike gene. All the strains have the footprint of the Wuhan virus.

\begin{tabular}{|c|c|c|c|c|c|c|c|c|c|c|}
\hline \multirow[t]{2}{*}{ Virus strain } & \multicolumn{10}{|c|}{ Nucleotide positions } \\
\hline & 56 & 284 & 333 & 1355 & 1433 & 1450 & 1841 & 2848 & 3183 & 3213 \\
\hline Wuhan & $\mathrm{C}$ & $\mathrm{C}$ & $\mathrm{T}$ & $\mathrm{T}$ & $\mathrm{C}$ & G & A & G & $\mathrm{C}$ & A \\
\hline B.1.617 & $\mathrm{C}$ & $\mathrm{C}$ & $\mathrm{T}$ & G & $\mathrm{C}$ & $\mathrm{C}$ & G & G & $\mathrm{C}$ & - \\
\hline B.1.617.1 & $\mathrm{C}$ & $\mathrm{T}$ & $\mathrm{C}$ & G & $\mathrm{C}$ & $\mathrm{C}$ & $\mathrm{G}$ & G & $\mathrm{C}$ & $\mathrm{T}$ \\
\hline B.1.617.2 & G & $\mathrm{C}$ & $\mathrm{T}$ & G & A & G & G & A & $\mathrm{T}$ & A \\
\hline B.1.617.3 & G & $\mathrm{C}$ & $\mathrm{T}$ & G & $\mathrm{C}$ & $\mathrm{C}$ & $\mathrm{G}$ & A & $\mathrm{C}$ & A \\
\hline
\end{tabular}

A-Adenine, $\mathrm{G}$ - Guanine, $\mathrm{C}$-Cytosine, and T-Thymine.

Table 2: Amino acid composition of the virus strains in the spike glycoprotein. All virus strains have footprint of Wuhan virus. The three strains of B.1.617 have more basic amino acid residues ( $\mathrm{K}$ and $\mathrm{R}$ ) indicating higher infectivity.

\begin{tabular}{|c|c|c|c|c|c|c|c|c|c|c|c|}
\hline \multirow[t]{2}{*}{$\begin{array}{l}\text { Variant } \\
\text { name }\end{array}$} & \multicolumn{11}{|c|}{ Amino acid positions } \\
\hline & 19 & 95 & 142 & 154 & 452 & 478 & 484 & 614 & 950 & 1071 & 1072 \\
\hline Wuhan & $\mathrm{T}$ & $\mathrm{T}$ & G & $\mathrm{E}$ & $\mathrm{L}$ & $\mathrm{T}$ & $\mathrm{E}$ & $\mathrm{D}$ & $\mathrm{D}$ & Q & $\mathrm{E}$ \\
\hline B.1.617 & $\mathrm{T}$ & $\mathrm{T}$ & G & E & $\mathrm{R}$ & $\mathrm{T}$ & Q & G & $\mathrm{D}$ & - & E \\
\hline B.1.617.1 & $\mathrm{T}$ & I & $\mathrm{D}$ & K & $\mathrm{R}$ & $\mathrm{T}$ & Q & G & $\mathrm{D}$ & $\mathrm{H}$ & $\mathrm{E}$ \\
\hline B.1.617.2 & $\mathrm{R}$ & $\mathrm{T}$ & $\mathrm{D}$ & $\mathrm{E}$ & $\mathrm{R}$ & $\mathrm{K}$ & $\mathrm{E}$ & G & $\mathrm{N}$ & Q & $\mathrm{E}$ \\
\hline B.1.617.3 & $\mathrm{R}$ & $\mathrm{T}$ & $\mathrm{D}$ & E & $\mathrm{R}$ & $\mathrm{T}$ & Q & $\mathrm{G}$ & $\mathrm{N}$ & Q & $\mathrm{K}$ \\
\hline
\end{tabular}

T-Threonine, R-Arginine, I-Isoleucine, G-Glycine, D-Aspartic acid, E-Glutamic acid, K-Lysine, L-Leucine, R-Arginine, Q-Glutarnine, and N-Asparagine. 


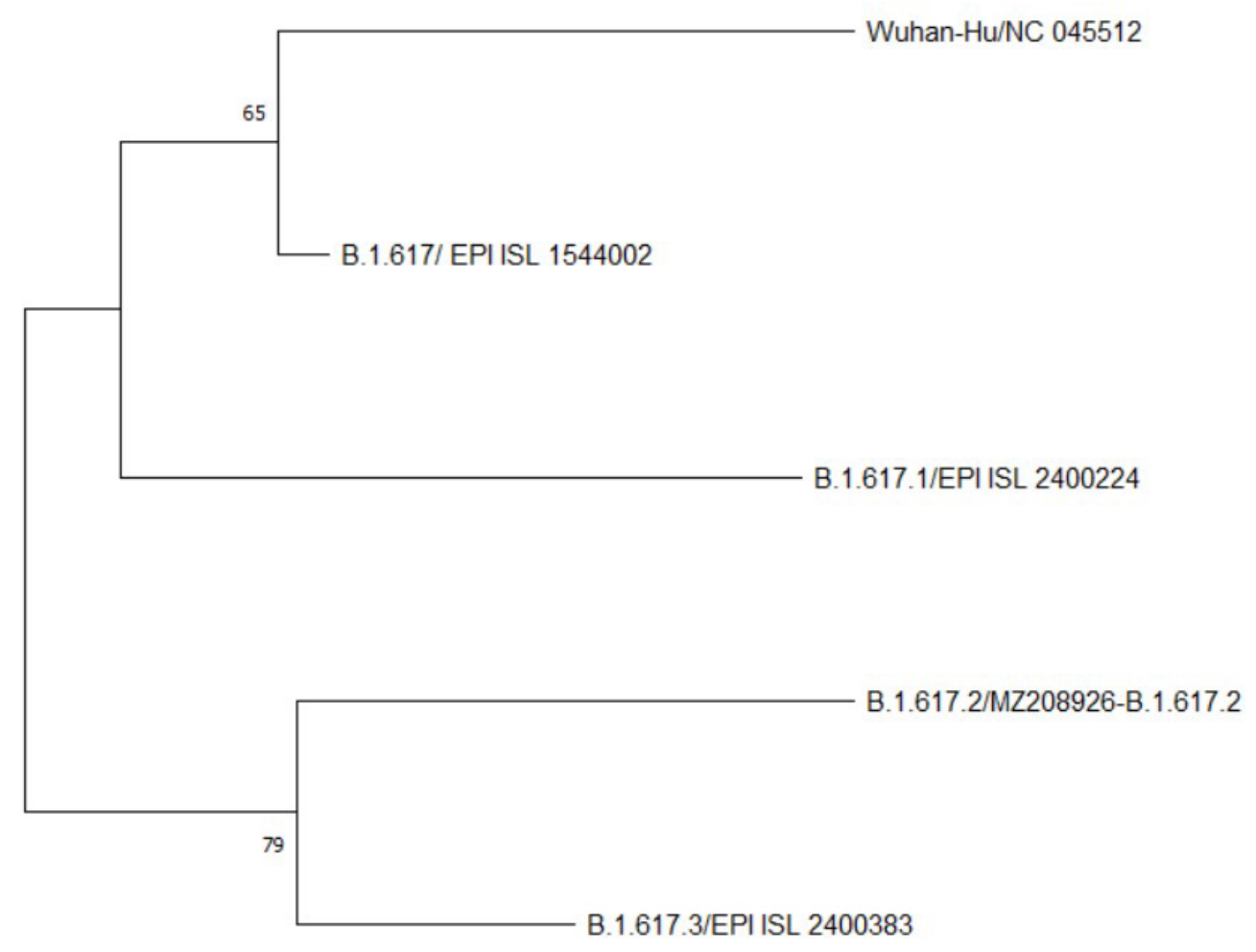

Figure 3: The Phylogenetic tree showing evolutionary relationships among the spike gene of SARS-CoV-2 variants.

the ACE genes. Low mortality is linked to the ACE II genotype, that is more prevalent in East Asian countries compared to the Africa and Europe [50]. Active substances found in garlic (Allium sativum L.) have an inhibitory effect on the human ACE2 protein and also on the main viral protease PDB ID 6LU7 (33.8 -kDa 3CLPro) of SARS-CoV-2, and thereby may confer coronavirus resistance and anti-coronavirus activity [51]. The $3 \mathrm{p} 21.31$ gene is identified linked to susceptibility in patients with respiratory failure [52]. The ABO blood-group system also plays a role in respiratory sickness.

\subsection{Seroconversion and Seroprevalence}

Antibodies to $\mathrm{S}$ protein were associated with the absence of clinical symptoms in health workers, and antibodies to $\mathrm{S}$ and $\mathrm{N}$ were linked to a reduction in risk of re-infection for a period of six months [53]. Anti-nucleocapsid antibodies had a half-life of 85 days, whereas anti-spike IgG remained detected up to 180 days. Analysis of previous studies, involving about 400,000 people in 23 countries, estimated COVID-19 seroprevalence at $0.37-22.1 \%$, with a pooled estimate of $3.38 \%$ [54]. The use of rapid IgM/ IgG tests is highly sensitive as well as specific in determining previous exposure to the virus [55]. Strong antibody response to the accessory protein ORF8 has been detected in COVID-19 patients [56]. The detection of SARS-CoV-2 strains having deletions of different nucleotide length in ORF8, combined with a strong immune response against ORF8, suggested that the absence of ORF8 may lead to immune evasion by the virus [26].

\section{CURRENT AND FUTURE MANAGEMENT OF COVID-19}

Neutralizing antibodies elicited by prior infection/ vaccination will determine future protection against SARS-CoV-2. Previous immunity may not protect against antigenic variants. The variants B.1.351, B.1.617, and P.1 escaped from neutralization by post-vaccination antibodies in North America and continued circulating, and a third dose of vaccine was needed to reduce virus transmission [57]. Furthermore, the B.1.617.1 kappa variant was $>6$-fold more resistant to neutralization by and post-vaccinal and convalescent sera [58]. Hamster antibodies against the B.1 variant with D614G were not efficient in neutralizing B.1.1.28.2, a P.2 variant [32]. Investigations in the U.K. revealed that following single dose of the Pfizer-BioNTech COVID-19 vaccine, the level of antibodies in vaccinates against delta variant B.1.617.2 was lower than those against Alpha variant B.1.1.7 indicating antigenic difference between the two variants/ mutants (UCL News, 4 June 2021). Looking at the epidemiology of the disease in the second wave in India, and associated delta and kappa variants of B.1 SARS-CoV-2, it appears that the antibody against virus infection elicited in the population during the prior (first) wave of COVID-19 possibly could not effectively contain the variants due to antigenic/ epitope difference. It has been predicted that the Delta B.1 variant may ignite the third wave of the disease (Prof. Neil Ferguson, London; PTI London, 10 June 2021), that indicates antigenic divergence of the delta strain from other circulating virus strains. 
Application of monoclonal antibodies (both virus neutralizing and non-neutralizing) and overlapping hexapeptides will explore the epitope structure of the virus and identify critical amino acid residues involved. It has been reported that monoclonal antibody resistant (MAR) mutants/ neutralization escape mutants with changes in the RBD and N-terminal domain of the $\mathrm{S}$ gene can readily be selected [59]. Mutations involving RBD in the Spike gene of the virus are of concern as it binds to the host ACE2 to initiate infection, and is an important antigenic determinant as well as the target of virus neutralising antibodies [60]. The D614 $\rightarrow \mathrm{G}$ mutation in the Spike gene that arose in China during the first wave of the disease, rapidly spread the world over and got established [61]. Of late, the Delta variant B.1.617.2, following its appearance in India, has subsequently been detected in about 62 countries, and there are reports (sources in Internet) that some COVID-19 vaccine brands have been upgraded with the new sequence. While this manuscript was being written, isolation of a P.2 variant, named B.1.1.28.2, from travellers from U.K. and Brazil was reported in India. The P.2 variant was not only more pathogenic than the B.1 D614G variant in hamsters, but also the serum of hamsters infected with the B.1 variant could not effectively neutralize the B.1.1.28.2 virus that warrants screening the vaccines for efficacy [32]. By whole genome ultradeep sequencing, Kemp et al. (2020) identified virus strain having less sensitivity to neutralisation by antibodies in an immunosuppressed patient who was treated with plasma from convalescent individuals. Amongst RNA viruses, CoVs have a mutation rate at around 23 nucleotide substitutions per year [63]. To mutate is the inherent nature of + sense RNA viruses, and the phenomenon of Quasispecies [64] do occur that is characterized by nucleotide sequence variation/ heterogeneity even in plaque purified virus populations; most mutants perish but a few get established and circulate. As the in-use COVID-19 vaccines do not confer sterile immunity, unlike some negative sense RNA virus diseases of man and animals caused by Morbillivirus (measles, PPR, and rinderpest etc) and Rhabdovirus (rabies), there are chances of selection of neutralization escape mutants upon circulation of the virus in partially immune population. As learnt from foot and mouth disease (FMD) control in the world through multiple vaccination with inactivated and multivalent virus vaccines (FMD; an extremely contagious disease of livestock and wild ungulates, and elephants caused by Aphthovirus that also carries + sense RNA genome as in SARS-CoV-2), for effective control of viral diseases against which available vaccines do not confer sterile immunity, (1) the vaccination strategy has to be so that the susceptible population (up to $80 \%$ ) is vaccinated in minimum possible time span (vaccination uniformity in time and density) to build herd/ population immunity, (2) co-circulation of virus and antibodies in vaccinated but superinfected and persistently infected individuals including suspected carriers may lead to selection of neutralization- escape virus mutants,(3) epitope mapping to qualify variants and mutants in relation to the vaccine candidate, (4) optimally high antigen dose with new generation adjuvant is required to elicit longer duration of effective immunity of at least 12 months, (5) companion diagnostics to detect antibodies against select NSPs of the SARS-CoV-2, viz., 3CL-protesae, ORF8, and RdRp etc, in vaccinated populations to monitor virus circulation and elimination, and (6) frequent occurrence of variants calls for detailed studies for selection of appropriate vaccine virus strains/ sequences. The selection and emergence of antigenic variants can be circumvented by increasing the vaccination coverage in all countries, and it may also be required to revaccinate against antigenic variants [65]. Asymmetric antigenic relationship observed between strains by Yadav et al. (2021) is of epidemiological significance. Therefore, the virus candidate/ sequence selected for formulating vaccine(s) has to be antigenically dominant over other strains in circulation. It is sure that even if the existing COVID-19 vaccines may not offer sterile immunity and need to be administered at intervals, protective antibodies elicited will limit virus replication in the host with resultant reduction in excretion of the virus by the host thereby decrease in R0 (R zero; basic reproduction number) value; controlling $\mathrm{R} 0$ value to $<1$ will result in control of the disease. However, during the post pandemic period when the virus transmission in the human population is controlled, at the same time the virus may look for alternate mammal hosts available around human beings. CoVs are known to infect mammals and birds, including dogs, cats, pigs and chickens. In India and elsewhere, there are reports of infection with SARS-CoV-2 in zoo animals. Death of one lioness on 03 June 2021 at a Zoological Park in Vandalur, Tamil Nadu, with SARS-CoV-2 infection and symptoms, and nine more lions positive for the viral genome was reported (The Times of India and The English Post, June 4, 2021, Chennai). The animal handlers and helpers at the Zoo are reported to be vaccinated against COVID-19. A male tiger at Ranchi Zoo is also reported dead following COVID- like symptoms (The Times of India, June 4, 2021, Chennai). Prior to this, in March 2020, an ill tiger at the Bronx Zoo, NY, USA, was detected positive for the virus. Earlier, infection of pet dog and cat with COVID-19 virus was detected in Hongkong and Belgium, respectively. Oreshkova et al. (2020) detected SARS-CoV-2 infection in minks and reported that infected humans can transmit the virus to minks. The virus also infects ferrets' upper respiratory tract [68].

\section{CONCLUSIONS}

CoVs have great potential for interspecies transmission. In view of this, Russia has initiated vaccination of pet animals against COVID-19 with a newly developed vaccine named 'CarnivacCoV'. Prolonged circulation of the SARS-CoV-2 in humans can lead not only to the selection of mutant virus populations with antigenic difference, but also facilitate interspecies transmission (reverse zoonoses) of the virus to animals close to humans, and further complicate the epidemiology, virology and control of the Coronavirus. While this manuscript was being written, a Delta Plus variant virus characterised by an additional asynonymous mutation at the position 417 (Lys to Asn) of the S protein of the delta variant was detected in M.P. state, India on 17 June 2021; this mutation is also found in the B.1.351 variant (AIIMS, Bhopal, and HT, 17 June, New Delhi). To summarise, the issue of possible co-circulation of the virus in COVID-19 vaccinated population is always possible to challenge the disease control program, and this needs to be monitored in real-time by using serological diagnostics and genomics. Application of higher techniques in molecular epidemiology will be useful in understanding and monitoring evolution and circulation of the virus in time and space, but tools in epitope mapping/ profiling will elucidate antigenic make up of genomic variants in relation to the vaccine sequence that has a direct bearing on efficacy and robustness of the vaccines in use. 


\section{ACKNOWLEDGEMENTS}

The authors would like to acknowledge National Institute of Veterinary Epidemiology and Disease Informatics, JSS Academy of Higher Education \& Research, Amrita School of Arts and Sciences and Davangere University for the infrastructure support.

\section{FUNDING}

There is no funding to report.

\section{CONFLICT OF INTEREST}

No potential conflict of interest between authors in publishing this work.

\section{ETHICAL APPROVALS}

This study does not involve experiments on animals or human subjects.

\section{DATA AVAILABILITY}

All data generated and analyzed are included within this research article.

\section{PUBLISHER'S NOTE}

This journal remains neutral with regard to jurisdictional claims in published institutional affiliation.

\section{REFERENCES}

1. Nuthalapati P, Ghanta MK, Natesh NS, Bhaskar LVKS. Association of hypercoagulation with severe acute respiratory syndrome coronavirus 2 infection. Blood Res 2021;56 (2):61-4.

2. Ghorbani A, Samarfard S, Ramezani A, Izadpanah K, Afsharifar A, Eskandari, $\mathrm{MH}$, et al. Quasi-species nature and differential gene expression of severe acute respiratory syndrome coronavirus 2 and phylogenetic analysis of a novel Iranian strain. Infect Genet Evol 2020;85:104556.

3. Lu R, Zhao X, Li J, Niu P, Yang B, Wu H, et al. Genomic characterisation and epidemiology of 2019 novel coronavirus: implications for virus origins and receptor binding. Lancet 2020;395(10224):565-74.

4. Phan T. Genetic diversity and evolution of SARS-CoV-2. Infect Genet Evol 2020;81:104260.

5. Kim SJ, Nguyen VG, Park YH, Park BK, Chung HC. A novel synonymous mutation of SARS-CoV-2: is this possible to affect their antigenicity and immunogenicity? Vaccines 2020;8(2):220.

6. Wu F, Zhao S, Yu B, Chen YM, Wang W, Song ZG, et al. A new coronavirus associated with human respiratory disease in China. Nature 2020;579(7798):265-9.

7. Loeffelholz MJ, Tang YW. Laboratory diagnosis of emerging human coronavirus infections-the state of the art. Emerg Microbes Infect 2020;9(1):747-56.

8. Chan JFW, Kok KH, Zhu Z, Chu H, To KKW, Yuan S, et al. Genomic characterization of the 2019 novel human-pathogenic coronavirus isolated from a patient with atypical pneumonia after visiting Wuhan. Emerg Microbes Infect 2020;9(1):221-36.

9. Liu X, Zhang B, Jin Z, Yang H, Rao Z. Structure of Mpro from COVID-19 virus and discovery of its inhibitors. Nature 2020;582(7811):289-93.

10. Chitranshi N, Gupta VK, Rajput R, Godinez A, Pushpitha K, Shen $\mathrm{T}$, et al. Evolving geographic diversity in SARS-CoV2 and in silico analysis of replicating enzyme 3CL pro targeting repurposed drug candidates. J Transl Med 2020;18(1):1-15.

11. Dharmashekara C, Pradeep S, Prasad SK, Jain AS, Syed A, Prasad KS, et al. Virtual screening of potential phyto-candidates as therapeutic leads against SARS-CoV-2 infection. Environ Challs 2021;100136.

12. Sanchez-Morgado JM, Poynter S, Morris TH. Molecular characterization of a virulent canine coronavirus BGF strain. Virus Res 2004;104(1):27-31.

13. Drosten C, Günther S, Preiser W, Van Der Werf S, Brodt HR, Becker $\mathrm{S}$, et al. Identification of a novel coronavirus in patients with severe acute respiratory syndrome. N Engl J Med 2003;348(20):1967-76.

14. Cyranoski D. Mystery deepens over animal source of coronavirus. Nature 2020;579(7797):18-20.

15. Chu H, Chan JFW, Yuen TTT, Shuai H, Yuan S, Wang Y, et al. Comparative tropism, replication kinetics, and cell damage profiling of SARS-CoV-2 and SARS-CoV with implications for clinical manifestations, transmissibility, and laboratory studies of COVID-19: an observational study. Lancet Microbe 2020;1(1):e14-23.18.

16. Jarvis M.C. Aerosol transmission of SARS-CoV-2: physical principles and implications. Front Public Health 2020;8: 813.

17. Mishra SK, Tripathi T. One year update on the COVID-19 pandemic: where are we now? Acta Trop 2021;105778.

18. Cao C, He L, Tian Y, Qin Y, Sun H, Ding W, et al. Molecular epidemiology analysis of early variants of SARS-CoV-2 reveals the potential impact of mutations P504L and Y541C (NSP13) in the clinical COVID-19 outcomes. Infect Genet Evol 2021;92:104831.

19. Winger A, Caspari T. The spike of concern-the novel variants of SARS-CoV-2. Viruses 2020;13(6):1002.

20. Phan T. Novel coronavirus: from discovery to clinical diagnostics Infect Genet Evol 2020;79:104211.

21. Hassan SS, Aljabali AA, Panda PK, Ghosh S, Attrish D, Choudhury PP, et al. A unique view of SARS-CoV-2 through the lens of ORF8 protein. Comput Biol Med 2021;133:104380.

22. Grubaugh ND, Petrone ME, Holmes EC. We shouldn't worry when a virus mutates during disease outbreaks. Nat Microbiol 2020;5:529-30.

23. Lauring AS, Hodcroft AB. Genetic variants of SARS-CoV-2 - what do they mean? JAMA 2021;325:529-31.

24. Singh PK, Kulsum U, Rufai SB, Mudliar SR, Singh S. Mutations in SARS-CoV-2 leading to antigenic variations in spike protein: a challenge in vaccine development. J Lab Physicians 2020;12(2):154.

25. Roncati L, Palmieri B. What about the original antigenic sin of the humans versus SARS-CoV-2? Med Hypotheses 2020;142:109824.

26. Majumdar P, Niyogi S. ORF3a mutation associated with higher mortality rate in SARS-CoV-2 infection. Epidemiol Infect 2020;148:e262.

27. van Dorp L, Acman M, Richard D, Shaw LP, Ford CE, Ormond L, et $a l$. Emergence of genomic diversity and recurrent mutations in SARSCoV-2. Infect Genet Evol 2020;83:104351.

28. Wang C, Liu Z, Chen Z, Huang X, Xu M, He T, et al. The establishment of reference sequence for SARS-CoV-2 and variation analysis. J Med Virol 2020;92(6):667-74.

29. Yin, C. Genotyping coronavirus SARS-CoV-2: methods and implications. Genomics 2020;112(5):3588-96.

30. Nguyen TT, Pham TN, Van TD, Nguyen TT, Nguyen DTN, Le HNM, et al. Genetic diversity of SARS-CoV-2 and clinical, epidemiological characteristics of COVID-19 patients in Hanoi, Vietnam. PLoS One 2020;15(11): 0242537.

31. Su YC, Anderson DE, Young BE, Linster M, Zhu F, Jayakumar J, et al. Discovery and genomic characterization of a 382-nucleotide deletion in ORF7b and ORF8 during the early evolution of SARS-CoV-2. MBio 2020;11(4):e01610-20.

32. Tang JW, Tambyah PA, Hui DS. Emergence of a new SARS-CoV-2 variant in the UK. J Infect 2020;82(4):e27-8.

33. Islam MR, Hoque MN, Rahman MS. Genome-wide analysis of SARSCoV-2 virus strains circulating worldwide implicates heterogeneity. Sci Rep 2020;10:14004. 
34. Rambaut A, Holmes EC, O'Toole Á. A dynamic nomenclature proposal for SARS-CoV-2 lineages to assist genomic epidemiology. Nat Microbiol 2020;5:1403-7.

35. Samuel A, Stéphanie H, Vincent F, Laura V, Sabine T, Emmanuel L, et al. Rapid spread of the SARS-CoV-2 Delta variant in some French regions. Euro Surveill 2021;26:2100573.

36. Faria NR, Mellan TA, Whittaker C, Claro IM, da S Candido D, Mishra $\mathrm{S}$. Genomics and epidemiology of the P.1 SARS-CoV-2 lineage in Manaus, Brazil. Science 2021;372:815-21.

37. Janik E, Bartos M, Niemcewicz M, Gorniak L, Bijak M. SARS-CoV-2: outline, Prevention, and Decontamination. Pathogens 2021;10:114.

38. Sabino EC, Buss LF, Carvalho MPS, Prete Jr CA, Crispim MAE. Resurgence of COVID-19 in Manaus, Brazil, despite high seroprevalence. Lancet 2021;397:452-5.

39. Tegally H, Wilkinson E, Giovanetti M. Detection of a SARS-CoV-2 variant of concern in South Africa. Nature 2021;592:438-43 .

40. Majumdar P, Niyogi S. ORF3a mutation associated with higher mortality rate in SARS-CoV-2 infection. Epidemiol Infect 2020;148.

41. Zhang L, Jackson CB, Mou H, Ojha A, Rangarajan ES, Izard T, Farzan M, Choe, H. The D614G mutation in the SARS-CoV-2 spike protein reduces S1 shedding and increases infectivity. BioRxiv 2020;11(1):6013.

42. Yadav P, Mohandas S, Sarkale P, Nyayanit D, Shete A, Sahay R, Potdar V, Baradkar S, Gupta N, Sapkal G, Abraham P. Isolation of SARS-CoV-2 B. 1.1. 28.2 P2 variant and pathogenicity comparison with D614G variant in hamster model. BioRxiv 2021.

43. Mathur R, Rentsch CT, Morton CE, Hulme WJ, Schultze A, MacKenna B. Ethnic differences in SARS-CoV-2 infection and COVID-19related hospitalisation, intensive care unit admission, and death in 17 million adults in England: an observational cohort study using the OpenSAFELY platform. Lancet 2021;397:1711-24.

44. Johnson BA, Xie X, Kalveram B, Lokugamage KG, Muruato A, Zou J, et al. Furin cleavage site is key to SARS-CoV-2 pathogenesis. Nature 2020;591(7849):293-9.

45. Coronaviridae Study Group of the International Committee on Taxonomy of Viruses The species severe acute respiratory syndromerelated coronavirus: classifying 2019-nCoV and naming it SARSCoV-2. Nat Microbiol 2020;5:536-44.

46. Vankadari N. Overwhelming mutations or SNPs of SARS-CoV-2: a point of caution. Gene 2020;752:144792.

47. Debnath M, Banerjee M, Berk M. Genetic gateways to COVID-19 infection: Implications for risk, severity, and outcomes. FASEB J 2020;34(7):8787-95.

48. Rigat B, Hubert C, Alhenc-Gelas F, Cambien F, Corvol P, Soubrier F. An insertion/deletion polymorphism in the angiotensin I-converting enzyme gene accounting for half the variance of serum enzyme levels. J Clin Invest 1990;86(4):1343-6.

49. Saab YB, Gard PR, Overall ADJ. The geographic distribution of the ACE II genotype: a novel finding. Genet Res 2007;89(4):259-67.

50. Aung AK, Aitken T, Teh BM, Yu C, Ofori-Asenso R, Chin KL, et al. Angiotensin converting enzyme genotypes and mortality from COVID-19: an ecological study. J Infect 2020;81(6):961-5.

51. Thuy BTP, My TTA, Hai NTT, Hieu LT, Hoa TT, Thi Phuong Loan $\mathrm{H}$, et al. Investigation into SARS-CoV-2 resistance of compounds in garlic essential oil. ACS Omega 2020;5(14):8312-20.

52. Ellinghau D, Degenhardt F, Bujanda L, Buti M, Albillos A, Invernizzi $\mathrm{P}$, et al. The $\mathrm{ABO}$ blood group locus and a chromosome 3 gene cluster associate with SARS-CoV-2 respiratory failure in an Italian-Spanish genome-wide association analysis. MedRxiv 2020.

53. Lumley SF, O'Donnell D, Stoesser NE, Matthews PC, Howarth A, Hatch SB, et al. Antibody status and incidence of SARS-CoV-2 infection in health care workers. N Engl J Med 2021;384(6):533-40.

54. Rostami A, Sepidarkish M, Leeflang M, Riahi SM, Shiadeh MN, Esfandyari $\mathrm{S}$, et al. SARS-CoV-2 seroprevalence worldwide: a systematic review and meta-analysis. Clin Microbiol Infect 2020;27(3):331-40
55. Hoffman $T$, Nissen $K$, Krambrich J, Rönnberg B, Akaberi D, Esmaeilzadeh M, et al. Evaluation of a COVID-19 IgM and IgG rapid test; an efficient tool for assessment of past exposure to SARS-CoV-2. Infect Ecol Epidemiol 2020;10(1):1754538.

56. Hassan SS, Choudhury PP, Roy B. SARS-CoV2 envelope protein: non-synonymous mutations and its consequences. Genomics 2020;112(6):3890-2.

57. Quinonez E, Vahed M, Shahraki AH, Mirsaeidi M. Structural Analysis of the Novel Variants of SARS-CoV-2 and Forecasting in North America. Viruses 2021; 13(5):930.

58. Focosi D, Tuccori M, Baj A, Maggi F. SARS-CoV-2 Variants: a synopsis of in vitro efficacy data of convalescent plasma, currently marketed vaccines, and monoclonal antibodies. Viruses 2021;13:1211.

59. Weisblum Y, Schmidt F, Zhang F, DaSilva J, Poston D, Lorenzi JC, et $a l$. Escape from neutralizing antibodies by SARS-CoV-2 spike protein variants. Elife 2020;9:e61312.

60. Kemp SA, Collier DA, Datir R, Ferreira IA, Gayed S, Jahun A, et al Neutralising antibodies in Spike mediated SARS-CoV-2 adaptation. Nature 2020;592(7853):277-82.

61. Korber B, Fischer WM, Gnanakaran S, Yoon H, Theiler J, Abfalterer $\mathrm{W}$, et al. Tracking changes in SARS-CoV-2 Spike: evidence that D614G increases infectivity of the COVID-19 virus. Cell 2020;182(4):812-27.

62. Kemp SA, Collier DA, Datir R, Ferreira I, Gayed S, Jahun A, et al. Neutralising antibodies in Spike mediated SARS-CoV-2 adaptation. medRxiv [Preprint]. 2020 Dec 29:2020.12.05.20241927.

63. Domingo E, Perales C. Viral quasispecies. PLoS Genet 2019;15(10): e1008271.

64. Fenollar F, Mediannikov O, Maurin M, Devaux C, Colson P, Levasseur A, et al. Mink, SARS CoV-2 and the Human-Animal interface. Front Microbiol 2021;12:1-12.

65. Oude Munnink BB, Sikkema RS, Nieuwenhuijse DF, Molenaar RJ, Munger E, Molenkamp R, et al. Transmission of SARS-CoV-2 on mink farms between humans and mink and back to humans. Science 2021;371:172-7.

66. Yadav P, Mohandas S, Sarkale P, Nyayanit D, Shete A, Sahay R, et al. Isolation of SARS-CoV-2 B. 1.1. 28.2 P2 variant and pathogenicity comparison with D614G variant in hamster model. BioRxiv 2020.

67. Oreshkova N, Molenaar RJ, Vreman S, Harders F, Munnink BBO, Hakze-van Der Honing RW, et al. SARS-CoV-2 infection in farmed minks, the Netherlands, April and May 2020. Euro Surveill 2020;25(23):2001005.

68. Shi J, Wen Z, Zhong G, Yang H, Wang C, Huang B, et al. Susceptibility of ferrets, cats, dogs, and other domesticated animals to SARScoronavirus 2. Science 2020;368(6494):1016-20.

How to cite this article:

Patil SS, Shivamallu C, Dharmashekara C, Pradeep S, Suresh KP, Ashwini Prasad, Kollur SP, Yadav MP, Chandrashekar Srinivasa, Pattnaik B. Diversity due to mutations in circulating virus strains of SARS-CoV-2 may delay control of COVID-19. J Appl Biol Biotech 2022;10(02):198-205. 